\title{
TREATMENT OF COMPLEX TIBIAL FRACTURES TYPES V AND VI OF SCHATZKER CLASSIFICATION BY DOUBLE PLATE FIXATION WITH SINGLE ANTERIOR INCISION
}

\author{
Thoguluva Chandra Sekaran Prem Kumar'1, M. N. Karthi²
}

${ }_{1}^{1}$ Senior Assistant Professor, Department of Orthopaedics, Madurai Medical College, Madurai, Tamilnadu.

${ }^{2}$ Senior Assistant Professor, Department of Orthopaedics, Madurai Medical College, Madurai, Tamilnadu.

\section{BACKGROUND}

ABSTRACT

High velocity injuries of knee joint are always associated with complex proximal tibial fractures, Schatzker classification type V and VI and these fractures are always associated with high complication rates. There are various treatment modalities available for these fractures.

Aims and Objectives- To analyse the results of double plating with single anterior incision in complex proximal tibial fractures (Types V and VI of Schatzker classification).

\section{MATERIALS AND METHODS}

This case series of 30 patients ( 24 males and 6 females) with Types V and VI of Schatzker classification of proximal tibial fractures (12 cases were Type V and 24 cases were Type VI) were treated by double plating with single anterior incision method between Sep. 2012 and Aug. 2015. Functional and radiological outcome was assessed using Modified Rasmussen's clinical and radiological criteria.

\section{RESULTS}

36 patients with tibial plateau fractures Schatzker type V and VI admitted at Government Rajaji Hospital, Madurai were included in this study. All the patients were treated with dual plating using single midline approach. The longest follow-up period was 20 months and shortest follow-up period was 6 months. Mean follow-up period was 14 months. Follow-up analysis was made using Modified Rasmussen's Clinical and Radiological Criteria. In our study, 33.33\% of the patients were in active productive age group (20 - 30 years). $83.33 \%$ of the patients were male. There was no significant difference in the side affected (Rt. side- 20 patients, Lt. side- 16 patients). All the patients in this study sustained injury due to road traffic accident. $66.7 \%$ of patients had Schatzker type VI fracture and 33.3\% had Schatzker type V fracture. In this study $27.7 \%$ patients had excellent outcome, 52.77\% patients had good outcome, $19.44 \%$ patients had fair outcome and none had poor outcome. In this study, only one patient developed deep infection with wound necrosis who was treated with IV antibiotics, debridement and flap cover was done and implant removal was done after 6 months. 4 patients with superficial infections were treated with antibiotics and regular dressing. One patient had mild valgus deformity, which did not interfere with her activities of daily living.

\section{CONCLUSION}

Single anterior midline approach and dual plating for tibial plateau fractures Schatzker type V and VI resulted in satisfactory clinical and radiological outcomes.

\section{KEYWORDS}

Tibial Plateau Fracture, Single Incision, Double Plate Osteosynthesis.

HOW TO CITE THIS ARTICLE: Kumar TCSP, Karthi MN. Treatment of complex tibial fractures types V and VI of Schatzker classification by double plate fixation with single anterior incision. J. Evolution Med. Dent. Sci. 2018;7(16):1940-1944, DOI: $10.14260 /$ jemds/2018/437

\section{BACKGROUND}

High velocity injuries of knee joint are always associated with complex proximal tibial fractures, Schatzker classification type V and VI and these fractures are always associated with high complication rates. There are various treatment modalities available for these fractures. These bicondylar fractures are with significant articular depression; multiple, displaced condylar fractures; metaphyseal-diaphyseal fractures with comminution; and open injuries and extensive closed injuries.[1-3]

'Financial or Other Competing Interest': None.

Submission 12-03-2018, Peer Review 01-04-2018,

Acceptance 04-04-2018, Published 16-04-2018.

Corresponding Author:

Dr. M. N. Karthi

Senior Assistant Professor, Department of Orthopaedics,

Madurai Medical College, Madurai, Tamilnadu.

E-mail:mn_karthi@yahoo.com

DOI: $10.14260 /$ jemds $/ 2018 / 437$

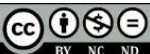

Both the complexity and the soft-tissue disruption of these types of fractures contribute to the high rate of unsatisfactory results for both conservative and surgical treatment.

The goals of operative treatment of these fractures include anatomic reduction and restoration of articular congruity, alignment and stable fixation to allow early motion. Dual plating is preferred to other techniques in the scenario of a significantly displaced articular fractures, especially in cases with significantly depressed fragments. $[4,5,6]$

This technique when performed through a single, midline extensile or double incision with wide stripping of the proximal tibia, has been associated with deep infection, wound dehiscence and soft tissue complications in $23 \%$ to $100 \%$ of patients. ${ }^{[7-10]}$

The most common drawbacks of these fractures treating with double plating with two or single incisions are skin and soft tissue problems, which invites a high rate of 
complications following attempted open reduction and internal fixation and poor bone quality and comminuted fracture patterns causing difficulty in achieving stable fixation. $[3,6,8-10]$

The aim of this study was to evaluate the results of double plating with single anterior midline incision in complex proximal tibial fractures (Types V and VI of Schatzker classification) and compare this rate to other studies in the literature.

\section{MATERIALS AND METHODS}

This case series of 36 patients ( 30 males and 6 females) with complex proximal tibial fractures were treated by double plating with single anterior midline incision between Sep. 2012 and Aug. 2015.

The fractures were classified using the Schatzker classification and open fractures were classified according to the method of Gustilo and co-workers. 12 cases were Type V and 24 cases were Type VI of Schatzker classification. 12 patients had open fracture (6 cases were Type I and 6 cases were Type II of Gustilo classification). There were 30 males and 6 females.

All patients underwent anterior-posterior (AP) and lateral radiographs as well as CT scans to identify the fracture configuration.

Definitive fixation was done by dual plating with single anterior midline incision technique after the soft tissue healing. The time from injury to definitive fixation varied widely (range: 0 to 21 days) as a result of variable degree of soft tissue injury noted at the time of presentation.

Closed fractures were treated with single anterior midline incision and double plate fixation.

Open fractures were managed by two-staged procedure, initially with saline irrigation, debridement and then by fixation.

\section{Anaesthesia}

Spinal anaesthesia was used in all patients.

\section{Position}

Supine position.

\section{Surgical Approach}

Single anterior midline approach. Incision was made in midline extending from superior of patella. Distal extension of the incision depends on the fracture length and length of the implant. Incision over the tibia was made $1 \mathrm{~cm}$ lateral to the tibial crest.

\section{Surgical Technique}

Medial and lateral flaps elevated to expose both the condyles. Fracture configuration was verified with $\mathrm{C}$-arm. Depressed fracture fragments, if present identified and elevated using an osteotome. The resulting void, if present, was filled with autologous corticocancellous bone graft harvested from the iliac crest. Fracture of both the condyles reduced using point reduction clamp and fixed temporarily with $\mathrm{K}$-wires. After verifying the articular congruity under C-arm, less comminuted condyle fixed first followed by fixation of the other condyle. Proximal tibial locking plate/ buttress plate used for lateral condyle and buttress plate used for fixation of medial condyle.

\section{Postoperative Follow-Up}

Patients were treated with IV antibiotics for 5 days postoperatively. Suction drain was removed on POD 2. Limb elevation was advised for all patients. EOT was done on POD 2, 5, 8 and POD 10. Sutures were removed on POD 12.

Patients were mobilised as early as possible. Patients were made to sit on first POD. Ankle pump and quadriceps exercises were performed from second POD. Knee bending exercises were started after the pain subsides and as tolerated by the patient.

Partial weight bearing using walkers started after 6 weeks and full weight bearing was allowed after $3-4$ months depending upon the union of the fracture site. Physical therapy was continued until range of motion and muscle strength was regained. Postoperatively, patients were evaluated with x-ray AP and lateral views. After postop x-ray, serial $\mathrm{x}$-rays were taken at 6 weeks, 6 months and 1 year.

Functional and radiological outcomes were assessed by Modified Rasmussen's clinical and radiological criteria.

\section{Functional Outcome}

The functional outcome was assessed with Modified Rasmussen's clinical criteria, which includes pain (maximum points- 6), working capacity (maximum points- 6), knee extension (maximum points- 4), range of motion (maximum points- 6), stability (maximum points- 6) and power of quadriceps (maximum points- 2) with maximum total points 30. Results were graded as excellent (28 - 30), good (24 - 27), fair $(20-23)$ and poor $(<20)$.

\section{RADIOLOGICAL ASSESSMENT}

Radiological outcome was assessed with Modified Rasmussen's radiological criteria at the end of 6 months. Criteria includes articular depression (maximum points- 3), condylar widening (maximum points- 3 ), varus or valgus angulation (maximum points- 3) and osteoarthosis (maximum point- 1). Results were graded as excellent (9-10), good (7-8), fair (5-6) and poor $(<5)$.

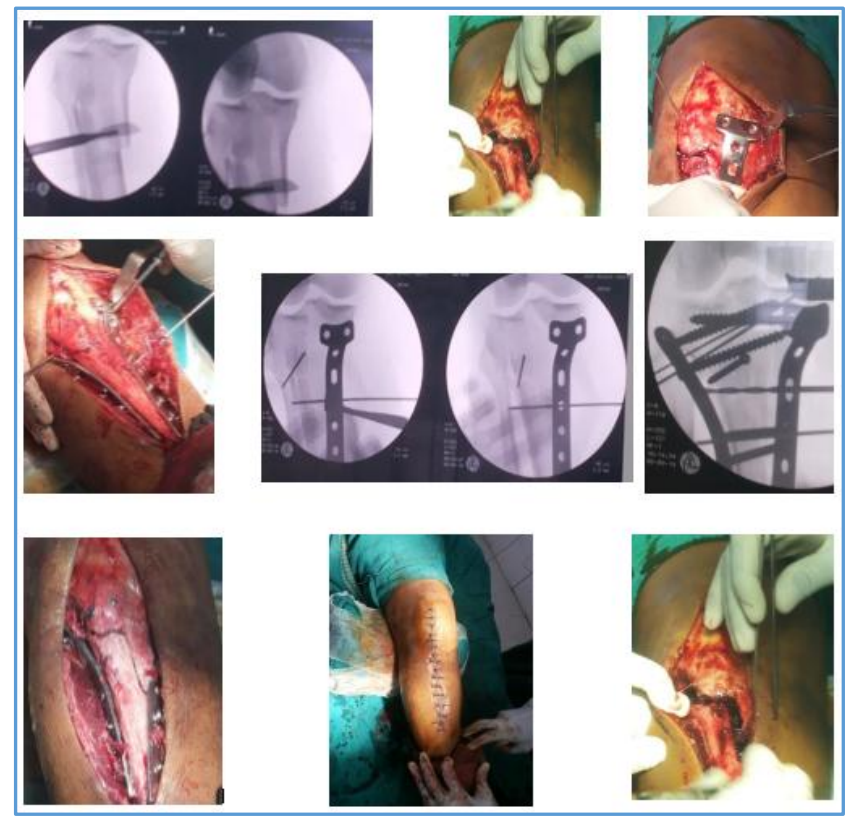

Figures. Intraoperative Pictures of Clinical and C-Arm Fluoroscopy 


\section{RESULTS}

36 patients with tibial plateau fractures Schatzker type V and VI admitted at Government Rajaji Hospital, Madurai were included in this study. All the patients were treated with dual plating using single midline approach. The longest follow-up period was 20 months and shortest follow-up period was 6 months. Mean follow-up period was 14 months. Follow-up analysis was made using Modified Rasmussen's Clinical and Radiological Criteria.

In our study, $33.33 \%$ of the patients were in active productive age group (20 - 30 years). $83.33 \%$ of the patients were male. There was no significant difference in the side affected (Rt. side- 20 patients, Lt. side- 16 patients). All the patients in this study sustained injury due to road traffic accident. $66.7 \%$ of patients had Schatzker type VI fracture and $33.3 \%$ had Schatzker type V fracture.

In this study $27.77 \%$ patients had excellent outcome, $52.77 \%$ patients had good outcome, $19.44 \%$ patients had fair outcome and none had poor outcome.

In this study, only one patient developed deep infection with wound necrosis who was treated with IV antibiotics, debridement and flap cover was done and implant removal was done after 6 months. 4 patients with superficial infections were treated with antibiotics and regular dressing. One patient had mild valgus deformity, which did not interfere with her activities of daily living.

Tables. Clinical Data of 36 patients with Complex Proximal Tibial Fractures (Types V and VI of Schatzker Classification) treated by Double Plate Fixation with Single Anterior Incision

\begin{tabular}{|c|c|c|}
\hline Age (Years) & Frequency & Percentage \\
\hline $20-30$ & 12 & 33.33 \\
\hline $31-40$ & 8 & 22.22 \\
\hline $41-50$ & 8 & 22.22 \\
\hline $51-60$ & 6 & 16.67 \\
\hline $61-70$ & 2 & 5.55 \\
\hline Total & $\mathbf{3 6}$ & $\mathbf{1 0 0}$ \\
\hline
\end{tabular}

\begin{tabular}{|c|c|c|}
\hline Sex & Frequency & Percentage \\
\hline Male & 30 & 83.33 \\
\hline Female & 6 & 16.67 \\
\hline Total & $\mathbf{3 6}$ & $\mathbf{1 0 0}$ \\
\hline
\end{tabular}

\begin{tabular}{|c|c|c|}
\hline Mode of Injury & Frequency & Percentage \\
\hline $\begin{array}{c}\text { Road Traffic } \\
\text { Accident }\end{array}$ & 36 & 100 \\
\hline Total & $\mathbf{3 6}$ & $\mathbf{1 0 0}$ \\
\hline
\end{tabular}

\begin{tabular}{|c|c|c|}
\hline Side & Frequency & Percentage \\
\hline Right & 20 & 55.55 \\
\hline Left & 16 & 44.44 \\
\hline
\end{tabular}

\begin{tabular}{|c|c|c|}
\hline Schatzker Type & Frequency & Percentage \\
\hline Type V & 12 & 33.3 \\
\hline Type VI & 24 & 66.7 \\
\hline Total & $\mathbf{3 6}$ & $\mathbf{1 0 0}$ \\
\hline
\end{tabular}

\begin{tabular}{|c|c|c|}
\hline Simple vs. Open & Frequency & Percentage \\
\hline Simple & 24 & 66.67 \\
\hline Compound Grade I & 6 & 16.67 \\
\hline Total & $\mathbf{3 6}$ & $\mathbf{1 0 0}$ \\
\hline
\end{tabular}

\begin{tabular}{|c|c|c|}
\hline $\begin{array}{c}\text { Time Interval } \\
\text { (Days) }\end{array}$ & No. of Cases & Percentage \\
\hline $0-7$ & 6 & 16.67 \\
\hline $8-14$ & 24 & 66.67 \\
\hline
\end{tabular}

\section{Complications}

One patient developed deep infection with wound necrosis who was treated with IV antibiotics, debridement and flap cover was done and implant removal was done after 6 months. 4 patients with superficial infections were treated with antibiotics and regular dressing. One patient had mild valgus deformity, which did not interfere with her activities of daily living.

\begin{tabular}{|c|c|c|}
\hline Complications & Frequency & Percentage \\
\hline Deep infection & 1 & 2.77 \\
\hline $\begin{array}{c}\text { Infection and } \\
\text { wound necrosis }\end{array}$ & 4 & 11.11 \\
\hline Valgus deformity & 1 & 2.77 \\
\hline Normal & 30 & 83.33 \\
\hline Total & $\mathbf{3 6}$ & $\mathbf{1 0 0}$ \\
\hline
\end{tabular}

Tables. The Results of 36 patients with Complex Tibial Plateau Fractures (Types V and VI of Schatzker Classification) treated by Double Plate Fixation with Single Anterior Incision according Modified Rasmussen Score

\begin{tabular}{|c|c|c|}
\hline Results & No. of Cases & Percentage \\
\hline Excellent & 10 & 27.77 \\
\hline Good & 19 & 52.77 \\
\hline Fair & 7 & 19.44 \\
\hline Poor & 0 & 0 \\
\hline Total & $\mathbf{3 6}$ & $\mathbf{1 0 0}$ \\
\hline
\end{tabular}

\section{DISCUSSION}

Tibial plateau fractures, one of the commonest intra-articular fractures occurring as a result of RTA, fall from height, violence etc. The management of these fractures has always been a subject of debate, because of their variety and complexity. High energy intra-articular fractures of the tibial plateau cause ongoing management problems and remains challenging for orthopaedic surgeons till date. Due to availability of many approaches and fixation methods for these fractures, a debate is still in place whether which approach and fixation option is ideal for these fractures to obtain better outcomes.

In this study functional outcome of tibial plateau fractures Schatzker type V and VI, treated by dual plating using single midline approach in 36 cases were analysed using Modified Rasmussen Criteria for Clinical and Radiological outcome.

In this study, tibial plateau fractures were more commonly seen in the active productive age group (20 - 30 years) due to high-energy trauma. Conservative management of these fractures cannot reduce depressed or displaced fracture fragments. This necessitates surgical management in most displaced and unstable fractures. It is extremely important to adequately visualise the fragments, reduce the fracture, regain articular congruity and obtain stable rigid fixation. In our series majority of patients were male $(83.33 \%)$, as they were involved mostly in road traffic 
accidents due to their occupation. There was no significant difference in the side affected in this study (right- 20 and left- 16 patients).

One patient developed deep infection with wound necrosis who was treated with IV antibiotics, debridement and flap cover was done and implant removal was done after 6 months. 4 patients with superficial infections were treated with antibiotics and regular dressing. One patient had mild valgus deformity, which did not interfere with her activities of daily living. All patients had mild restriction of range of motion.

In a study conducted by Kye-Youl $\mathrm{Cho}^{11}$ et al using single midline approach, only one patient had delayed wound healing. Ebrahim et al ${ }^{12}$ stated that none of the patients developed wound complications following single midline incision in 22 patients in his study. In our study, one patient had wound necrosis. Even though one patient developed wound necrosis, when comparing with other studies incidence of wound complications was not much high.

Ebrahim et $\mathrm{al}^{12}$ stated that 2 patients developed superficial infections, but none had deep infection in their study using single midline approach. Kye-Youl $\mathrm{Cho}^{11}$ et al stated that there was no superficial or deep infection in his study using single midline approach. Stevens ${ }^{13}$ et al and Shah 14 et al using dual incision also reported superficial and deep infections in their study, but the incidence was low. In our study, only one patient developed deep infection. When comparing other studies using single midline approach and dual incisions, incidence of infection was low in both approaches if the surgery was done once the soft tissue condition improved.

In a study conducted by Waddell et $\mathrm{al}^{15}$ patients w e r e treated with single lateral plating who developed varus malunion at the fracture site. Zheng ${ }^{16}$ et al stated that patients treated with dual plating provided better stability and none of the patients developed malunion. When comparing to the above studies, none of the patients developed malunion in our study. This clearly shows dual plating offers better stability than single lateral plating.

Kye-Youl $\mathrm{Cho}^{11}$ stated that none of the patients had delayed or non-union in their study. In our study also, all the fractures were united between 3 and 4 months.

In the study conducted by Ebrahim et al,12 none of the patients had varus or valgus malalignment. But in our study, one patient developed valgus malalignment. This could be due to ligamentous injury sustained during the initial trauma. In spite of these complications associated with these fractures and their management using this technique we achieved excellent results in $27.77 \%$ of patients, good results in $52.77 \%$ of patients, fair results in $19.44 \%$ of patients and none had poor results.

\section{Limitations of the Study}

Short-term follow-up, surgery done by different surgeons and all fractures included in this study were caused by road traffic accidents.

\section{CONCLUSION}

1. Single midline approach allows better visualisation of fracture geometry of both tibial condyles and fracture reduction with low incidence of infection and wound complications if the surgery was done once the soft tissue condition improved.

2. Dual plating provides better stability, buttress effect for both the condyles and good alignment of the limb.

3. Dual plating prevents malunion and also avoids delayed or non-union of both the condyles.

To conclude, single anterior midline approach and dual plating for tibial plateau fractures, Schatzker type V and VI resulted in satisfactory clinical and radiological outcomes.

\section{REFERENCES}

[1] Mallik AR, Covall DJ, Whitelaw GP. Internal versus external fixation of bicondylar tibial plateau fractures. Orthop Rev 1992;21(12):1433-6.

[2] Su EP, Westrich GH, Rana AJ, et al. Operative treatment of tibial plateau fractures in patients older than 55 years. Clin Orthop Relat Res 2004;(421):2408.

[3] Raykov D, Ivanov S, Apostolov P. Tibial plateau fractures - standard and specific surgical approaches. Scripta Scientifica Medica 2013;45(3):74-81.

[4] Neogi DS, Trikha V, Mishra KK, et al. Comparative study of single lateral locked plating versus double plating in type $\mathrm{C}$ bicondylar tibial plateau fractures. Indian J Orthop 2015;49(2):193-8.

[5] Apley AG. Fractures of lateral tibial condyle treated by skeletal traction and early mobilization: a review of sixty cases with special reference to the long-term results. J Bone \& Joint Surg Br 1956;38-B(3):699-708.

[6] Brown GA, Sprague BL. Cast brace treatment for plateau and bicondylar fractures of the proximal tibia. Clin Orthop Relat Res 1976;(119):184-93.

[7] Sirkin MS, Bono CM, Reilly MC, et al. Percutaneous methods of tibial plateau fixation. Clin Orthop Relat Res 2000;(375):60-8.

[8] Waddell JP. Fracture of the tibial plateau in tibia and fibula. Courtbrown C, Penning D, eds. Oxford: Butterworth Heinemann 2000: p. 38-54.

[9] Palmer I. Compression fractures of lateral tibial condyle and their treatment. J Bone \& Joint Surg 1939;2(Am):674.

[10] Palmer I. Fractures of the upper end of tibia. J Bone \& Joint Surg Br 1951;33B(2):160-6.

[11] Cho KY, Oh HS, Yoo JH, et al. Treatment of Schatzker type V and VI tibial plateau fractures using a midline longitudinal incision and dual plating. Knee Surg Relat Res 2013;25(2):77-83.

[12] Hassankhani EG, Kashani FO, Hassankhani GG. Treatment of complex proximal tibial fractures (types V \& VI of Schautzker Classification) by double plate fixation with single anterior incision. Open J of Orthopedics 2013;3:208-12.

[13] Stevens DG, Beharry R, McKee MD, et al. The long term functional outcome of operatively treated tibial plateau fractures. J Orthop Trauma 2001;15(5):31220.

[14] Shah SN, Karunakar MA. Early wound complications after operative treatment of high energy tibial plateau fractures through two incisions. Bull NYU Hosp Jt Dis 2007;65(2):115-9. 
[15] Waddell JP, Johnston DW, Neidre A. Fractures of the tibial plateau: a review of ninety five patients and comparison of treatment methods. J Trauma 1981;21(5):376-81.
[16] Yu Z, Zheng L, Zhang Y, et al. Functional and radiological evaluations of high energy tibial plateau fractures treated with double buttress plate fixation. European Journal of Medical Research 2009;14(5):200-5. 